\title{
A Qualitative Analysis of ELT in the Language Institutes of Iran in the Light of the Theory of 'World Englishes'
}

\author{
Reza Pishghadam \\ Ferdowsi University of Mashhad, Iran \\ Email: pishghadam@um.ac.ir \\ Fahimeh Saboori \\ Ferdowsi University of Mashhad, Iran \\ Email: saboori@um.ac.ir
}

\begin{abstract}
This study seeks to analyze English language teaching and learning in the informal context of education in Iran from the perspective of the theory of "World Englishes". The qualitative data consisted of a total of 182-minute recording of 25 subjects' interviews and observation of seven 100-minute classes. The results revealed that most Iranian teachers' and learners' viewpoints are in contrast with the key concepts and tenets of the theory of "World Englishes" and that their teaching and learning practices are far from adherence to this theory. These findings further supported the claim that Iran's ELT still lives in the modernist era by believing in a world English rather than world Englishes and in the importance of conforming to it.
\end{abstract}

Index Terms — native speaker, modernism, standard English, world Englishes

\section{INTRODUCTION}

Followed by lots of innovations, emanating from the postmodernist theories which underscore the role of pluralistic options in science, it seems that education in general has underwent radical changes in the light of postmodernist notions. One of the manifestations of postmodernism in second language education is the theory of World Englishes. This theory highlights the diversity of English language, holding the view the there is no one Standard English (Kachru, 1991).

The remarks of the Nigerian writer, Chinua Achebe, best express the opposition to the adoption of a Standard English and highlights the legitimacy of new Englishes which are developed through acculturation and indigenization of English, i.e., influencing English language by local cultures and languages (Kirkpatrick, 2007).

I feel that English language will be able to carry the weight of my African experience ...But it will have to be a new English, still in communication with its ancestral home but altered to suit its new African surroundings (Achebe, 1975, p. 62, cited in Widdowson, 2003, p.42).

This way he urges the non-native English-using countries to develop a kind of nativised English which best suits their context of use, reflects their nationality, and is capable of expressing their own experience and way of thinking.

To the knowledge of the researchers, since there is a paucity of research into the theory of World Englishes in the context of Iran, this study aims at analyzing English teaching and learning in the informal context of education in Iran, from both descriptive and explanatory perspectives, in the light of the theory of World Englishes.

\section{THEORETICAL BACKGROUND}

The coinage and promotion of the term World Englishes is mainly associated with Kachru (1982). The remarkable influence of Kachru in this field is not confined to his writing of many books and articles; but is also clearly evident in his editorship of the academic journal World Englishes as well as his being responsible for anchoring the annual conferences on world Englishes held by the International Association for World Englishes (IAWE). The underlying philosophy of Kachruvian approach argues for the "importance of inclusivity and pluricentricity in approaches to linguistics of new varieties of English" and deals with some other related topics including creative writing, critical linguistics, pedagogy, pidgin and creole studies, and the sociology of language (Bolton, 2004, p. 367).

Bhatt (2001), also, argued that World Englishes paradigm particularly emphasizes multilingualism, multicultural identities, multiple norms of use, and bilinguals' creativity. Moreover, representing liberation linguistics ideology, it severely problematizes the sacred cows of the traditional theoretical and applied linguistics including interference, interlanguage, native speaker, speech community, Standard English, and traditional English canon. 
World Englishes has its philosophical roots in the two dominant schools of thought of the present time, i.e., Postcolonialism and Postmodernism.

Postcolonialism, according to Bressler (2007), emerges from colonialization period in the 19th century when Great Britain was "the largest colonizer and imperial power" in the world (p. 236). But this political, social, economic and ideological domination of England gradually started to disappear by the turn of the century through a process called decolonization, which reached its peak in 1950, by the independence of India. It was the birth of postcolonialism as a liberation movement.

Postcolonialism accounts for the radical social changes occurred during Postmodern era which led to "a significant delegitimization of authority and to a more egalitarian society" (Pishghadam \& Mirzaee, 2008, p. 5). The aim of postcolonialism is to destablize the stabilized institutions, and in SLA, in particular, decolonizing the colonized ELT is its main goal (Bressler, 2007). Some of its common themes include national identity, resistance, appreciation of differences, and protection of indigenous languages and cultures. Postcolonialism is much similar to postmodernism in its subjects and concerns.

In order to arrive at a full understanding of postmodernism, it is better to set out with a brief explanation of modernism, from which it has developed.

Modernism, as a linear positivist movement, is rooted in the European Enlightenment starting in the mid-18 $8^{\text {th }}$ century (Pishghadam \& Mirzaee, 2008). It is based on the role of observation and scientific method and highlights the significance of objectivity, reductionism and rationality. All in all, the scientific and social advancements of that period led to such great vanity that man considered himself as the center of the universe and believed in the possibility of finding the ultimate truth, and in the ideas of the best and absoluteness.

Postmodernism, on the other hand, as a nonlinear constructivist movement, believes in a world with no center, where relativism (vs. absolutism) and subjectivism (vs. objectivism) as the two dominant viewpoints of the time, cast doubt on all the formerly taken-for-granted beliefs and where the deluding ideas of the best and the perfect no more make sense (Pishghadam \& Mirzaee, 2008). This era, starting in the late $20^{\text {th }}$ century, is also marked with a belief in the death of metanarratives and grand theories, claiming that no one can ever find the ultimate truth. It, instead, sheds light on the significance of pragmatism and calls for trying different methods and styles and evaluating them based on their appropriateness and applicability to the given context. In the same vein, it moves toward divergence through the appreciation of differences and celebrating local reality, truth, and values.

One of the cornerstones in the theoretical foundation of World Englishes is communicative competence (Berns, 2006; Kachru \& Nelson, 1996). It, in fact, occupies a fundamental position in World Englishes discourse and this high significance lies in the fact that, by highlighting the interdependence between the notion of appropriateness and the sociocultural context, it embraces a pluricentric view of language use. The case of speech acts is a good example here. Cross-cultural studies reveal that speech acts have different linguistic realizations from one culture to another and it is the sociocultural context that determines which linguistic realization is the appropriate one in a given situation.

Still, another reason concerning the importance of communicative competence to world Englishes involves its questioning the validity of a standard English (Berns, 2006). It is argued that, since each setting has its own cultural and social values and since local norms are shaped in accordance with these values, each setting calls for its own nativized variety of English, the one that corresponds to its set of values and norms. As a result, it seems quite absurd to think that Standard English-which culturally represents the Judeo-Christian tradition-can be used cross-culturally and in different international settings without impeding successful communication and intelligibility. It follows that no single communicative competence can claim the capacity to match all different local cultures and settings.

All in all, World Englishes ideology denies the validity of communicative competence as a monolithic notion just as it opposes the adoption of a variety as a standard and model (Berns, 2006, p. 723).

In fact, one of the most important achievements of World Englishes in the last three decades has been to challenge the standard language ideology and replacing it by the liberation linguistics ideology (Bolton, 2004; Bhatt, 2001). The standard language ideology, according to Bolton (2004), is the traditional view in English studies which has awarded the American and British English the authority to provide and prescribe the norms of usage in all international English using contexts.

This tension between the prescription of a world standard English and the legitimacy and autonomy of world Englishes calls to mind the double-voicedness of Bakhtin's (1994) centripetal and centrifugal forces. Centripetal forces, as a modernist feature, are those calling for centralizing, homogenizing and convergence, which in the present context, contribute to the conformity to an authoritative and prescriptive standard variety which is believed to be the best. On the other hand, centrifugal forces, as a postmodernist feature, involve decentralizing and divergence and thus appreciate the diverse features and functions of English worldwide.

As pointed out earlier, liberation linguistics severely confronts the traditional Standard English ideology, in an attempt to legitimate and empower the new varieties of English as well as their speakers.

Representing such liberation ideology, Milroy and Milroy (1999) argued that prescribing a standard variety is in fact bestowing prestige to just one variety at the expense of suppressing all the others (cited in Davis, 2006).

Widdowson (2003) argued that the main importance of Standard English lies in a belief in its guaranteeing effective communication and standards of intelligibility. In his view, Standard English, which is usually defined in reference to 
its grammar and lexis, is primarily a written variety sanctioned for institutional use. Furthermore, he believed that Standard English is a shibboleth, marking the right sort of person. He elaborated on this issue arguing that while grammatical conformity, due to the in-built redundancy of language, is not crucial for effective communication, Standard English places much importance on it (rather than on lexis). The reason, according to Widdowson, is that grammar "is so often redundant in communicative transactions that it takes on another significance, namely that of expressing social identity" and so adopts the role of a distinguisher between members of the community and the outsiders (p. 39).

Moreover, Widdowson (2003) striped the attitudinal goodness totally away from Standard English by noting the double standards concerning the issue. He elaborated on it explaining that the stability implied by Standard English is in contrast with the dynamic nature of language and that while Standard English calls for conformity, "proficiency only comes with nonconformity" (p. 42). So you are proficient in English to the extent that you do not conform to Standard English and do not submit to what it dictates to you. In other words, mastery means taking the possession of the language, bending it to your advantage, developing innovations in it, and being able to speak your mind rather than speaking the language.

The ideology of World Englishes, in the same vein, calls the label native speaker into serious question and strongly denies a special status for it. It specially opposes the prevailing view that native speakers are necessarily better at speaking English and hence they would make better English teachers (Jenkins, 2003). Moreover, it argues that since English is used for international communication and is, thus, used among speakers from different nationalities, it simply makes no sense to talk of its non-native speakers. This argument gets even more powerful when one considers the ever increasing situations in which English is used as a lingua franca among its L2 speakers rather than between its L1 and L2 speakers.

Cook (1995) made attempts to empower non-native speakers by proposing his multi-competence model (cited in Brown, 2007). According to the main tenet of this model, L2 user's mind is much more flexible than that of monolingual native speaker since they have access simultaneously to two competences rather than one; therefore, they have higher language and culture awareness. Thus, they should not be compared to monolingual native speakers; but should be considered in their own right.

Similarly, Widdowson (2003) strongly denied the native speakers' claim of the ownership of English language and their right to determine how it should be spoken around the world. He argued that the custodians of Standard English are not in fact natural native speakers but they are a minority of people, a particular self-elected subset of educated native speakers who have the power to impose this standard variety.

All in all, World Englishes is a relatively new theory, which has gained its worldwide currency only in the late 20th and early 21st centuries (Bolton, 2004). Having its philosophical roots in postmodernism and postcolonialism, this theory has remained somehow obscure in the modernist educational context of Iran (Pishghadam \& Mirzaee, 2008), and as far as the researchers know, there has been no study conducted in Iran in the field of English teaching and learning concerning World Englishes. So, due to this dearth of research in the educational context of Iran in this field, this study aims at revealing whether the main tenets of this theory have adherents among English teachers and learners and whether they are put into practice in this context.

\section{PURPOSE OF THE STUDY}

The main purpose of this study is to analyze English language learning and teaching in the language institutes in Iran, with respect to the theory of "World Englishes".

This study, therefore, is seeking to answer the following questions:

Q1: What are English teachers' attitudes toward the whole idea of World Englishes?

Q2: To what extent do English teachers practically adhere to the whole idea of World Englishes?

Q3: What are English learners' attitudes toward the whole idea of World Englishes?

Q4: To what extent do English learners practically adhere to the whole idea of World Englishes?

\section{METHODOLOGY}

\section{A. Participants and Setting}

This study was conducted on 25 participants, i.e. 13 teachers ( 2 males and 11 females, within the age range of 24 to 55) plus 12 learners ( 6 males and 6 females, within the age range of 18 to 30). The interviewed teachers included 4 M.A. graduates, 2 M.A. students, and 7 B.A. graduates in the fields of English language teaching and English language and literature.

One of the qualifications needed for the English learners to be chosen as the subjects of this study was their level of proficiency, i.e., they needed to be at intermediate or higher levels, since it is believed that at such levels they have already established a sense of what different varieties of English are, formed attitudes toward these varieties and have probably selected one as their own model. The researcher relied on the institutes' placement tests in determining the learners' level of proficiency. The participants were not chosen randomly from a larger population and the two criteria for choosing them were simply accessibility and their tendency to cooperate. 


\section{B. Instrumentation}

Two types of instrumentation were used in the present study. First, two sets of questions used in the interviews of the teachers and learners; Second, an open-ended checklist used in the observations of the classes.

It should be stated that both sets of questions and the checklist were designed in proper consultation with pertinent experts, and based on the key concepts of theory of "World Englishes" presented in the research and literature in this field reviewed earlier (e.g. Kachru, 1991; Widdowson, 2003) and the good guidelines they provided as to which phenomena are worthy of attention when exploring attitudes toward and adherence to this theory.

\section{Procedure}

The data collection started in January 2009 and took around four months.

As for the interviews, the subjects were interviewed based on the set of questions exploring their attitude toward and practical adherence to the key concepts of the theory of "World Englishes". The data of this part consisted of 182minute audio-recorded interviews (77 minutes of students' interviews and 105 minutes of teachers' interviews).

Teachers' interviews were conducted in English while those of students were conducted in Persian in order to get them to express themselves more exactly and easily as well as to remove their stress due to the presence of the recorder. These interviews were, then, transcribed and analyzed from the viewpoint of World Englishes through content analysis, i.e., reading and re-reading the transcriptions, and looking for similarities and differences in order to find themes and develop categories.

Furthermore, seven interviewed teachers' classes were observed based on the open-ended checklist. As mentioned earlier, the checklist was made according to the guidelines provided by the reviewed literature and research, highlighting the aspects of teaching which were worthy of attention when observing the classes. These include, for example, the use of L1 in the class, teaching of culture, error correction, and conformity to certain accents and varieties. These seven 100-minute observations were audio-recorded and the significant parts were, then, transcribed. Considering the fact that people do not always act the way they think they do, the primary reason for such observations was to see whether what the teachers believe was necessarily the same as what they actually did in their classes. These observations, also, allowed the researcher to gain better insight into what actually happened in class (possible practical adherence to the key concepts of World Englishes) and provided her with the helpful tools to interpret the results of the teachers' interviews.

As for the order of the last two procedures, observing the classes preceded interviewing the teachers in order to avoid making them conscious of what their classes were being observed for, and consequently prevent some possible changes in their teaching.

\section{RESUlts}

\section{A. Teachers' Interviews}

The results of this part revealed that most of the teachers considered American as the standard and best one to teach because "it's more common worldwide", "American is genuine, real, spoken by natives, it's not just made up".

They also considered new Englishes as unimportant and illegitimate varieties of English. The reason one of them gave is worthy of attention:

-"They are not acceptable because if you use them everyone understands you are foreigners and your speaking English is not good, they should be acceptable to the natives".

Not surprisingly, they considered students' familiarity with these new Englishes quite unnecessary, "Since they don't play any role in learning English, American accent is sufficient".

As for the use of L1 in the class, again most of the teachers stated that they never used Persian in their classes and that they did not let their students use it either because, according to some of them, it is the only opportunity students have, so you should put them in a completely English atmosphere, i.e., a normal situation and that the use of Persian turns it into an abnormal situation and brings about distraction to learning.

Two interesting reasons, two of the teachers referred to frankly, deserves much attention:

-"It (Persian) sometimes helps but, you know, our students think that if their teachers speak in Farsi, they are not knowledgeable enough to explain that in English, but in many cases I myself find it very helpful but because I think that my students might misjudge me, I never use it".

-"Since in that case students would start speaking in Persian and make English sentences according to Persian structures and grammar and this way everyone would understand they're speaking Persian English".

Regarding error correction, interestingly, all the interviewees stated that, especially in speaking, they just corrected the more important errors, or to use the terms some of them used, "the vital ones", "the crucial ones and as indirectly as possible", since correcting all the errors would be discouraging to the students and would make them lose their confidence.

But still three of them added they would correct all the errors if it was possible, in order to make them sound more native-like. 
Still another significant result of these interviews was that almost all of the teachers expressed their emphasis on introducing and teaching the American and British cultures and considered it one of the important parts of teaching English since:

-"One of the most important problems of our students is that they think in Persian and want to talk in English, if they know the culture, they will be able to speak in English better".

-"When you speak a language it's better to know everything about the culture and all its ups and downs, it shows that you are a native-like person and then if you would be in the English environment you wouldn't have any problems with native people".

As for trying to sound native-like, just three teachers stated that they did not mind it and that just correct pronunciation mattered to them, "because you are not a native, so why do you have to pretend to be a native?" one of them added.

Not surprisingly, all the other respondents expressed their high concern for, and great importance of, sounding native-like. Some common reasons they referred to include exposing students to native and original accents and being a good model for them, speaking real English and perfectly, and as the representatives of the textbooks they teach, not sounding different from what students hear on CDs.

Finally, confessing that they were indeed impressed by those who have good American or British accent, most of the teachers added that it did not, however, influence their evaluation or, at least, they tried so.

There is still another point repeatedly mentioned in the respondents' answers in order to justify their emphasis on conforming to a so-called standard variety, i.e. students' going to an English country. Considering the ratio of those students who are learning English in order to live or educate in an ENL country to all the others with other motivations, such reasons seem quite unjustified.

\section{B. Learners' Interviews}

The results of these interviews illustrated that most of the respondents highly preferred to have a native teacher since they believed that, all in all, native teachers are superior to the nonnative ones and, most interestingly, the main reason, they all referred to for this superiority, had to do with having better accent and pronunciation:

In addition, almost all of the respondents expected their teachers to have a native accent. One student stated that since we are learning another country's language, we need to obey all the rules of this language and its native accent because "the language is theirs and we don't have the right to make changes in it". She also added that just as when an American is learning Persian s/he tries to speak it with a native accent, we, as English learners, should make the same effort.

Further, according to another student, the teachers' having a native accent is important "since students are much influenced by their teachers" and, as a good handwriting makes you interested, "when a teacher speaks with a good accent, the desire (inclination) to speak with the same accent is evoked in the students".

These students, also, considered evaluation based on accent an acceptable criterion for evaluation since, as some of them put it, "it makes us try to acquire the same native accent".

As for error correction, most of the students believed that, ideally, it is better to correct all the errors, even the tiniest ones in order to learn perfectly.

Regarding the significance of familiarity with other varieties of English, two of the respondents, surprisingly, expressed their complete unfamiliarity with other varieties (other than American and British), saying that they had never heard any of them.

Further, seven students out of the other ten, considered familiarity with such varieties, and especially taking some time of the class to this end, quite unnecessary; "unless you are going to live in one of the countries with such varieties", some of them added.

As for the use of Persian in the class, half of the respondents were strongly against it due to the same reasons of its being the only opportunity for them in the EFL context of Iran and providing a normal situation in the class.

The other half of the respondents took a more moderate view stating that it is ok sometimes to use Persian in teaching grammar when students do not get the point or in some other cases when students cannot express themselves in English.

Finally, all the interviewees, except one, preferred their accent to be as native-like as possible mostly because they considered it an indicator of their perfect learning.

The only respondent who opposed this view stating that he did not mind having a nonnative accent explained the reason through a remarkable simile,: "our accent is like our face, it just says where we come from", so it suffices to be able to communicate successfully and there is no need to have a native-like accent.

To wrap this part up, it is worth analyzing the respondents' answers with an eye toward the aims and motivations they stated for studying English.

Among the twelve respondents, just one of them was planning to immigrate to an ENL country, i.e., the U.S.; two of them were going to immigrate to ESL countries of Malaysia and New Zealand; two of them were learning English for business; and the rest of them needed English in order to be able to use English books and journals related to their education and, also, to use computer and internet.

As evident in the interviews, there seems to be a discrepancy between respondents' motivations for learning English and their emphasis on learning and, speaking with, a native accent. Most interestingly, the respondent who was planning 
to live in Malaysia and the one who needed English to have business with Arab countries and India were among those who had the greatest of such emphasis.

\section{Observation}

The results of the observations are presented in four parts corresponding to the four important implications of World Englishes on English teaching, to which especial attention was granted while observing the classes.

1. Use of Persian in the Class

Just in two classes, the teachers sometimes used Persian and allowed their students to use it as well in some special cases. One of such cases was the teacher's giving a Persian equivalent for some English word after students did not get its meaning in spite of her explanation in English. Here is an example from the data:

1. T: So that person should be punished in some way, for example he or she should get suspended.

SS: Suspended? ((looking confused))

T: Yes, get suspended.

$\mathrm{S}$ : What's the meaning?

$\mathrm{T}$ : It means ...uh...to be forced to stay away from your job for a period of time.

S: Fire?

T: Not fired. It's just for a period of time. ((students still look confused)) Moa'llagh shodan \{get suspended\}

Another case was the teacher's giving a Persian equivalent for some expression or idiom. In such cases, again, the teacher first explained in English. This time students got it but still to make it more tangible to the students, the teacher preferred to provide them with the Persian meaning as well.

As mentioned earlier, students were also sometimes allowed to use Persian in the class. For instance, it was allowed to use Persian when they could not express what they had on their minds in English. Following is an example of this case:

2. S: After I left there, I got very sad for that, I mean, ...I am...I feel sorry because I didn't help him, I am really Pashimunam \{I regret it\}

T: Aha, so you regret that you didn't help him.

S: Yes, I regret that.

Still another case when the use of Persian in the class was allowed was stating few words as funny comments either by the teacher or by the students. Such funny comments, sometimes, changed the mood of the class and refreshed the students.

In the other five classes, teachers did not speak a word in Persian, though sometimes it seemed quite necessary and helpful. A case in point was when the students did not get what the teacher meant in spite of her explanations:

3. S: What's the meaning of potential here?

$\mathrm{T}$ : Here it means ...possibility.

S: They are synonyms?

$\mathrm{T}$ : Not always, the original meaning is the ability which is not developed yet.((students look confused)) for example, he has the potential for progress.((students still look confused but this time the teacher neglects it and goes on teaching))

These teachers did not let their students use Persian in their classes either, and one of them even made fun of them for doing this:

4. SS: $\mathrm{xxx}$

T: Hello? What's up there?

$\mathrm{S}$ : Writing vase jalase bade? \{is the writing for next session?\}

$\mathrm{T}$ : Are you speaking Bengali or what? I don't understand you.

S: ((somehow shy)) sorry ... is the writing for next session?

And also there was another case when a student tried to talk to her teacher about her problem with the grammar point in English but she could not express herself well, so she started speaking in Persian about it but she was not allowed and thus was interrupted by the teacher.

2. Error Correction

Although in the interviews all the teachers stated that they just corrected the more important errors and those which impede communication, the observation of four of their classes did not confirm it. These four teachers' corrections included the errors which seemed to be so trivial and sometimes just an indicator of the Persian accent. They corrected such errors by interrupting the students and giving them the right form or pronunciation and after that students usually repeated it. Here are some examples of such error corrections:

5. S: He knows how to use a computer $/ \mathrm{k} \Lambda \mathrm{m}$ 'pju:tər/

T: Computer/kəm'pju:tər/

6. S: It's important to have lot of informations=

$\mathrm{T}$ : Information, it's uncountable.

7. S: Turkish $/$ törki $/$ coffee $=$

T: Turkish /t3:kil/

8. S: If you don't have up-to-date information=

T: Up-to-dated 
9. S: It's quite necessary /ne'səsəri/ because $=$

T: Necessary /'nesəsəri/

10. S: Thomas $/$ töm $\Lambda \mathrm{s} /$ likes to $=$

T: Thomas $/ \Theta \Lambda$ mos/

11. S: He came from Toronto /'törentö/ so=

T: Toronto /t’'ra:ntö/

12. $\mathrm{S}$ : They met in a rainy day=

$\mathrm{T}: \underline{\text { On a rainy day }}$

3. Culture and Pragmatic Norms

Investigating the way teachers deal with teaching culture and pragmatic norms in English classes was relatively more difficult than investigating the other aspects since not every lesson in English textbooks highlights a significant cultural point. That is why, just in three of the seven classes significant points in teaching culture and pragmatic norms were observed. In one of these classes the teacher was teaching different English expressions used as greeting. He did not, however, talk about or refer to different greetings used in other cultures and countries and just taught the ones used in English culture:

13. T: How do you start a conversation in English? I mean the greetings, what are they?

SS: [How are you? [What's up?

T: Yes, nice ((teacher writes them on the board)) what else?

S: What's the news?

T: Yea, what's new ((writes it on the board)) what else?

SS: [How's everything? [xxx

T: Right, and how are things? How is it going? ((writes them on the board))

In another situation, the teacher explained the importance of dogs in English culture stating that in America, you cannot kick a dog away or insult it like here, "Dogs are so respectable there, they're members of families, you should be very careful how to treat them", he added.

Finally, another teacher explained the importance of your hairstyle and the way your hair looks in western countries. "It's so important for them that they even have an idiom about that, to have a bad hair day, it sometimes says about your personality and the kind of person you are", she stated.

As obvious in these examples, it seems that the teaching of cultural points and pragmatic norms in our English classes is confined to introducing and highlighting those of American and English cultures, and nothing about the culture of other English using countries is mentioned.

\section{Accent}

There were two contradictions between what teachers stated in their interviews and what they actually did in their classes. First, one of the teachers who had stated that having a native accent is important to him since he did not want to sound different from what students hear on the textbook CDs, had a British accent while the books he taught (Interchange) were American. And the second teacher who had stated that the accent you choose depends on the textbook you teach, had American accent while the textbook she taught (Rising Star) was British. In addition, in three of the observed classes, short discussions about English accents came up, in two of which the teachers just talked about and compared British and American accents. It was only the third class in which the teacher shortly referred to other English varieties and accents and highlighted the importance of having correct pronunciation over a good accent.

14. T: So, what's the difference between pronunciation and accent, do you know?

S: For example, in our country we have different accents, like Esfahani or Mashhadi accent, but pronunciation is a... is the base of word.

T: Can you give an example?

SS: In English?

T: yes, of course. ((the teacher laughs))

S: Water /wațr/in American and water /wötə(r)/ in British.

$\mathrm{T}$ : Very good, which one is better?

SS: [American [American is easier [American is better.

T: Easier to speak?

S: Yes, but British is easier to understand.

T: Aha, by the way, you didn't give an example for the difference between pronunciation and accent...((students thinking)) for example, it's water /wațər/, it's not water /vațər/, u see? / $/$ / is the correct pronunciation and /v/ is wrong... So which one is more important: pronunciation or accent?

SS: Pronunciation.

T: Why?

S: Because we have just one correct pronunciation but we have different accents.

T: Good, ok, do we have wrong accents? For example, can we say that Mashhadi accent is wrong and Tehrani accent is right?

SS: No. 
$\mathrm{T}$ : Or for example, Arabic or Indian accent is=

S: Not good.

T: Not good? Why? Is it wrong?

S: No, it's not wrong but it's not beautiful.

T: Aha, it's not beautiful in your opinion, but it's not wrong, yea? It's just like other accents, like American and British and Australian.

Finally, it was observed in another class that the teacher did not work on the pronunciation part of that unit in Interchange book (Richards, Hull, \& Proctor, 2005) -the part which was teaching a point in American accent (unreleased consonants) -and simply skipped it.

To conclude, the data gained from the observed classes -the exclusive use of English with no helpful systematic use of Persian in some classes, and correcting trivial errors and sometimes those relating to Persian accent, and sometimes too much emphasis on the stress of words, and also teaching and highlighting Judeo-Christian tradition while teaching English language, and finally, not familiarizing students with other varieties and accents of English -is in line with the results of interviews and, one the whole, confirms them.

\section{DISCUSSION}

The results of the interviews and observations are highly indicative of the fact that most of the teachers and learners consider American English to be the best and standard variety and also quite superior to the other accents. They also revealed the great emphasis these teachers and learners expressed on acquiring and speaking with this accent. The main problem with such view and efforts is that, as Kirkpatrick (2007) put it, "accents are closely bound up with feelings of personal and group identity" (p. 37); thus, the English learners who are obsessed with acquiring a native accent and do their best to speak with that accent are very likely to be subject to deculturation and loss of local identity (Pishghadam \& Kamyabi, 2008).

In addition, from a psychological perspective, such perfectionism in learning as well as teaching -in the from of correcting trivial errors and minute deviation from native norms -has been proven to have significant psychological hindering effects on the students learning (Akhoondpoor, 2008).

Another significant finding of this study was a belief in the traditional sacred cows of English among the interviewed teachers and learners. These sacred cows, according to Bhatt (2001), include native speaker, standard variety, and interlanguage.

As evident in the results of the students' interviews, most English learners preferred to have native teachers and thought that they were necessarily better at teaching, as well. This fact is an example of what Jenkins (2003) referred to as the bias against local teachers and for native ones displayed by English learners in the Outer and Expanding circle countries.

Moreover, some of the teachers' and learners' remarks were quite indicative of their beliefs in the idea of native speaker as the standard setter as well as the guardian and owner of true language and in the idea of American and British Englishes as the standard varieties of English to which we should conform.

The findings of this study regarding the emphasis on conformity to native norms, further, confirmed those of Timmis' (2002) survey in revealing a significant attachment to native speaker norms, especially in expanding circle countries, which was greater among learners than teachers.

In addition, the unwillingness and even reluctance some of the learners and teachers expressed in, respectively, getting familiar with new Englishes and using them in their classes illustrates that they consider such varieties as interlanguages which, according to Jenkins (2003), are seeking to reach the target language, and according to Bhatt (2001), rather than being regarded in their own rights, are constantly compared to the target language.

Such view about new Englishes (considering them to be unimportant and illegitimate) among English teachers has a serious consequence as well, namely, "linguistic insecurity", as Kachru and Nelson (1996) put it, which, in turn, leads to "linguistic prescriptivism" (p. 89). Regarding our case, it follows that the refusal to accept the existence of a Persian variety -or at least, accent -of English leads to regarding some Persian English pronunciation of words and the sentences made based on some Persian structures or pragmatic norms as errors and therefore correcting them (such corrections were observed in some classes and stated in some interviews).

This view point is exactly in line with the one calling for complete conformity to a so-called standard variety of English which was strongly problematized by Widdowson (2003) and Bakhtin (1981, cited in Lin \& Luke, 2005).

According to Widdowson (2003) such conformity implies stability which is in contrast with the dynamic nature of language and, by leaving no space for innovation and no opportunity for making the language yours by appropriating it for your needs and context, it literally impedes your proficiency in that language.

Similarly, Bakhtin (1981) opposed such linguistic prescriptivism by distinguishing between two kinds of discourses: authoritative discourse, i.e. "language or discourse imposed on person", and internally persuasive discourse, i.e. "hybridized and populated with one's own voices, styles, meanings, and intentions" (cited in Lin \& Luke, 2005, p. 9394). Making this distinction, he called for local creativity and heteroglossia in English classes and argued that, to this end, we should change English from an authoritative discourse to an internally persuasive one, "so that English can 
become a tool that students can use to construct their own preferred worlds, preferred identities, and preferred voices" (p. 94).

Another significant finding of this study was most teachers' and learners' preference for exclusive use of English in the class. While Cook (1995, cited in Brown, 2007), through his multi-competence model, called for the recognition of L1 in language classes and highlighted the great help systematic use of L1 can provide in learning an L2 and while Hancock's (1997) study problematized the long-standing assumption that all L2 use in the class is good and all L1 use is bad, these teachers and learners still believe that L1 use interferes will L2 learning and either hinders it or slows it down.

Such view among teachers and learners is seemingly interwoven with the wrong idea they have got of the normal situation of English around the world. As evident in some of their remarks, they still consider monolingualism to be the norm, while, due to the rapid global spread of English, long ago the norm has changed and turned into multilingualism and multiculturalism (Bolton, 2006; Kachru \& Nelson, 1996; Kirkpatrick, 2007; Skutnabb-Kangas, 1998, cited in Pennycook, 2004).

Finally, another significant point in the results of observations and teachers' interviews which deserves serious attention was that teaching of English in our classes, seemingly, acted as a "Trojan horse for the cultural values of its native speaker community" (Timmis, 2007, p. 125). Such enculturation can most clearly be evidenced in sentences like In English this speech act is like this while in English is, in fact, a disguise for in American or British culture. Such way of teaching English in our classes -whether consciously or unconsciously -is a realization of Kachru's (1991) statement, "English is essentially learnt as a tool to understand and teach the American and British cultural values, or which is generally termed the Judeo-Christian tradition"(p. 10, cited in Jenkins, 2003, p. 63).

It is, of course, unfair to direct all the blame to the teachers, here, ignoring the fact that a big part of this blame lies with the materials developers who, rather than aiming for "an intercultural communicative competence", as Alptekin (2002) put it, just present and highlight native speaker communicative competence in the textbooks (p. 63, cited in Timmis, 2007, p. 128).

\section{CONCLUSION}

The whole findings of this study can best be interpreted in light of research questions when presented in two parts: descriptive (describing the present situation), and explanatory (explaining why it is like this).

The descriptive part, which deals with the transcribed observation data, describes what actually happens in the English classes, i.e. teaching and learning practices. Based on the findings, American English was considered to be the best variety to teach and teachers were expected to have either American or British accent. Similarly, such findings revealed both learners' and teachers' great emphasis on conformity to the American (or British) English. This emphasis was quite evident in their efforts to sound native-like and their aiming for passing for natives and, also, in some teachers' error corrections - considering trivial deviations from these varieties as errors. Still, according to these results, both teachers and learners preferred the exclusive use of English in the class. In addition, they were quite unwilling to get familiar with new Englishes and use them in their classes. Finally, the teachers highlighted and prescribed American and British cultural norms in their classes and considered it as an important aspect of teaching English. Thus, regarding the second and fourth research questions, all these teaching and learning practices tend to assert that our ELT is seemingly far from adherence to the whole idea of the theory of "World Englishes".

The explanatory part, on the other hand, which is based on the transcribed interview data, discusses the reasons and derives behind such teaching and learning practices and, thus, deals with teachers' and learners' beliefs and attitudes. As discussed at length earlier, most teachers and learners believed in the American and British Englishes as the standard varieties of English - the real and genuine English -to which all English users should conform. They, also, believed in the special status of native speaker both as a perfect model in learning English and as a benchmark for measuring all English users' proficiencies in English. Furthermore, they regarded the variety of English they speak with as an interlanguage which should be constantly compared to the American or British Englishes and eventually match them. They, also, believed in monolingualism to be the norm and in American and British people as the owners of English whose culture should be taught along with it around the world. Finally, based on the findings, most teachers and learners considered new Englishes as illegitimate and unimportant varieties of English. Thus, regarding the first and third research questions, it seems that our English learners' and teachers' viewpoints are in complete contrast with the key concepts and tenets of the theory of "World Englishes", the ones which call for legitimacy and empowering the new varieties of English and strictly problematize any special status for native speaker and native varieties.

All in all, a remarkable macro-level ramifications of the whole findings of this study is that most of our teachers and learners still believe in a world English rather than world Englishes and that the ideas of "the best" and "the perfect" and the importance of unification have their followers among them. Thus, as Pishghadam and Mirzaee (2009) argued that Iran's educational system still lives in the modernist era -due to different reasons including teaching the same books all over the country and the existence of General Exam (unification) -it, unfortunately, seems that their claim is completely true about our ELT (our ELT is a clear confirmation for such claim).

The most important implication of this study can be bringing about an awareness, for both teachers and learners, of there being no best and standard variety of English, i.e., American and British Englishes are two varieties of English just the same as its other varieties, with no higher status. 
The immediate effect of this awareness, on teachers would be stopping them from trying to sound native-like, and on learners would be preventing them from placing a very high premium on acquiring and conforming to American or British Englishes.

In addition, considering the fact that, today, most communication through English is taking place within non-natives rather than with natives, the special status of native-speaker would lose its credit in their minds and, thus, they would aim their teaching at successful cross-cultural communication rather than intelligibility to native speakers.

As a consequence, teachers would no more consider students' trivial deviations from the native accent -in the form of Persian English pronunciation of some words -as errors and would, also, be more tolerant of students' English sentences made based on some Persian structures or pragmatic norms - as a sign of the Persian variety of English.

Furthermore, considering the fact that, today, the norm is multilingualism and multiculturalism, another result of this study can be encouraging teachers to regard their knowledge of another language and not being a monolingual as an asset and to appreciate their sharing an L1 with their students and, putting aside the dated assumption that English is best taught monolingually, to take advantage of the great their L1 can provide in their teaching.

Also, an interesting result of this study can be encouraging teachers to provide students with occasional exposure to different varieties in order to change learners' negative attitudes toward these varieties as well as familiarizing them with these varieties and their cultures.

In addition, the most remarkable outcome of this study for teachers will be making them treat the material and textbooks they are teaching more critically. Such critical view will be of special importance while dealing with teaching the English culture. Put simply, teachers would be more careful not to prescribe American and British cultural values and pragmatic norms presented in the textbooks. They would, instead, introduce them along with those of other English using cultures (including ours) and this way they would focus on an intercultural communicative competence and highlight the potential of English for representing different cultures.

Finally, the ultimate attainment of this study can contribute to a paradigm shift in English language teaching and testing, the one that puts aside the importance of native speaker both as a model in learning English and as a yardstick against which all the learners should be measured.

To wrap this part up, regarding Iran as an expanding circle country which has not yet developed its own variety of English, the researcher takes a view similar to that of Willis (1999) in urging teachers to expose their students to a native variety - which is in fact the only choice due to the available teaching material -but to adopt a conscious-raising methodology which places a very low premium on conformity (cited in Timmis, 2007). To clarify on such methodology, it is worth stating Willis' explanation:

See language as a meaning system and encourage learners to develop their own systems. Carry out C-R [consciousraising] work which encourages learners to focus on forms, but place a very low premium on testing for conformity. Cut out the focus on forms which have little communicative value (e.g. question tags). Look for productive generalizations (e.g. V+N+Infin) and pay much less attention to exceptions like suggest. (p. 136)

As is clear from any scientific research, nothing can be self evident unless verified by observation or experimentation. To do any type of observation or experiment, one may face with some limitations and problems. This study could have come to somewhat more different results than it did, if it were not confronted with the following limitations. First, because the study was conducted in Mashhad, the obtained findings cannot be safely generalized to other situations. Second, in this study gender was not taken into consideration as a variable, which can be a good topic for further research.

\section{REFERENCES}

[1] Achebe, C. (1975). Morning yet on creation day. London: Heinemann.

[2] Akhoondpoor, F. (2008). On the role of learner perfectionism in second language learning success and academic achievement. Unpublished master's thesis, Ferdowsi University of Mashhad, Iran.

[3] Alptekin, C. (2002). Towards intercultural competence in ELT. ELTJ, 56(1), 57-64.

[4] Bakhtin, M. M. (1981). The dialogic imagination: Four essays By M. M. Bakhtin, (C. Emerson \& M. Holoquist, Trans.). Austin: University of Texas Press.

[5] Bakhtin, M. M. (1994). The Dialogue Imagination, (M. Holoquist \& C. Emerson, Trans.). In S. Dentith (Ed.), Bakhtinian thought: An introductory reader (pp. 33-51). London: Routledge.

[6] Berns, M. (2006). World Englishes and communicative competence. In B. B. Kachru, Y. Kachru, \& C. L. Nelson (Eds.), The handbook of world Englishes (pp. 718-731). Oxford: Blachwell.

[7] Bhatt, R. M. (2001). World Englishes. Annual Reviews, 30, 527-550.

[8] Bolton, K. (2004). World Englishes. In A. Davis, \& C. Elder (Eds.), The handbook of applied linguistics (pp. 367-396). Oxford: Blackwell.

[9] Bolton, K. (2006). Varieties of world Englishes. In B. B. Kachru, Y. Kachru, \& C. L. Nelson. (Eds.), The handbook of world Englishes (pp. 289-313). Oxford: Blachwell.

[10] Bressler, C. E. (2007). Literary criticism: An introduction to theory and practice (4th ed.). NJ: Pearson education.

[11] Brown, H. D. (2007). Principles of language learning and teaching (5th ed.). White Plains, NY: Pearson Education.

[12] Cook, V. (1995). Multi-competence and the effects of age. In D. Singleton \& Z. Lengyel (Eds.), The age factor in second language acquisition (pp. 52-58). Clevedon, UK: Multilingual Matters. 
[13] Davis, A. (2004). The native speaker in applied linguistics. In A. Davis, \& C. Elder (Eds.), The handbook of applied linguistics (pp. 431-450). Oxford: Blackwell.

[14] Davis, D. R. (2006). World Englishes and descriptive grammars. In B. B. Kachru, Y. Kachru, \& C. L. Nelson (Eds.), The handbook of world Englishes (pp. 509-527). Oxford: Blackwell.

[15] Hancock, M. (1997). Behind classroom code switching: Layering and language choice in L2 learner interaction. TESOL Quarterly, 31, 217-235.

[16] Jenkins, J. (2003). World Englishes: A resource book for students. New York, NY: Routledge.

[17] Kachru, B. B. (Ed.) (1982). The other tongue: English across cultures. Urbana, IL: University of Illinois Press.

[18] Kachru, B. B. (1991). Liberation linguistics and the Quirk concern. English Today, 25, 3-13.

[19] Kachru, B. B., \& Nelson, C. L. (1996). World Englishes. In S. L. McKay, \& N. H. Hornberger (Eds.), Sociolinguistics and language teaching (pp. 71-102). Cambridge: Cambridge University Press.

[20] Kirkpatrick, A. (2007). World Englishes: Implications for international communication and English language teaching. Cambridge: Cambridge University Press.

[21] Lin, A. M. Y., \& Luk, J. C. M. (2005). Local creativity in the face of global domination: Insights of Bakhtin for teaching English for dialogic communication. In J. K. Hall, G. Vitanova, \& L. Marchenkova. (Eds.), Dialogue with Bakhtin on second and foreign language learning: New Perspectives (pp. 77-98). Mahwah, New Jersey: Lawrence Erlbaum.

[22] Mesthrie, B. (2006). Contact linguistics and world Englishes. In B. B. Kachru, Y. Kachru, \& C. L. Nelson (Eds.), The handbook of world Englishes (pp.273-289).Oxford: Blackwell.

[23] Milroy, J., \& Milroy, L. (1999). Authority in language: Investigating standard English, (3rd ed.). London/New York: Routledge.

[24] Pennycook, A. (2004). Critical applied linguistics. In A. Davis, \& C. Elder (Eds.), The handbook of applied linguistics. Oxford: Blackwell.

[25] Pishghadam, R., \& Kamyabi, A. (2008). On the relationship between cultural attachment and accent mimicry. Unpublished manuscript, Ferdowsi University of Mashhad.

[26] Pishghadam, R., \& Mirzaee, A. (2008). English language teaching in postmodern era. TELL, 2, 89-109.

[27] Pishghadam, R., \& Navari, S. (2009). Cultural literacy in language learning: Enrichment or derichment? A paper presented at UITM of Malaysia.

[28] Richards, J. C., Hull, J., \& Proctor, S. (2005). Interchange 3 ( $3^{\text {rd }}$ ed.). Cambridge: Cambridge University Press.

[29] Skutnabb-Kangas, T. (1998). Human rights and language wrongs - a future for diversity? Language Sciences, $20(1), 5-28$.

[30] Timmis, I. (2002). Native speaker norms and international English: A classroom view. ELTJ, 56(3), 240-249.

[31] Timmis, I. (2007). The attitudes of language learners towards target varieties of the language. In B. Tomlinson (Ed.), Language acquisition and development (pp. 122-139).

[32] Widdowson, H. D. (2003). Defining issues in English language teaching. Oxford: Oxford University Press.

[33] Willis, D. (1999). An international grammar of English? Unpublished paper, $33^{\text {rd }}$ IATEFL Conference, Edinburgh.

Reza Pishghadam is associate professor in TEFL. He is currently in Ferdowsi University of Mashhad, where he teaches Psychology of language education and Sociology of language education. He has published more than 40 articles and books in different journals. His major interests are: Psychology / Sociology of language education, and Language testing.

Fahimeh Saboori is an MA holder in TEFL. She has done her study in Ferdowsi University of Mashhad. She is currently teaching ESP in Ferdowsi University of Mashhad. Her major interests are: Psycholinguistics and Teaching methodology. 